This item was submitted to Loughborough's Research Repository by the author.

Items in Figshare are protected by copyright, with all rights reserved, unless otherwise indicated.

\title{
Copper coin-embedded printed circuit board for heat dissipation: manufacture, thermal simulation and reliability
}

\section{PLEASE CITE THE PUBLISHED VERSION}

http://dx.doi.org/10.1108/CW-11-2014-0052

\section{PUBLISHER}

(C) Emerald Group Publishing Limited

\section{VERSION}

AM (Accepted Manuscript)

\section{PUBLISHER STATEMENT}

This work is made available according to the conditions of the Creative Commons Attribution-NonCommercialNoDerivatives 4.0 International (CC BY-NC-ND 4.0) licence. Full details of this licence are available at: https://creativecommons.org/licenses/by-nc-nd/4.0/

\section{LICENCE}

CC BY-NC-ND 4.0

\section{REPOSITORY RECORD}

Chen, Yuanming, Shouxu Wang, Xuemei He, Wei He, Vadim V. Silberschmidt, and Ze Tan. 2019. "Copper Coin-embedded Printed Circuit Board for Heat Dissipation: Manufacture, Thermal Simulation and Reliability". figshare. https://hdl.handle.net/2134/23605. 


\title{
Copper coin-embedded printed circuit board for heat dissipation: manufacture, thermal simulation and reliability
}

\author{
Yuanming Chen \\ State Key Laboratory of Electronic Thin Films and Integrated Devices, University of Electronic Science and Technology of China, \\ Chengdu, China and Wolfson School of Mechanical and Manufacturing Engineering, Loughborough University, Loughborough, UK \\ Shouxu Wang and Xuemei He \\ State Key Laboratory of Electronic Thin Films and Integrated Devices, \\ University of Electronic Science and Technology of China, Chengdu, China \\ Wei He \\ State Key Laboratory of Electronic Thin Films and Integrated Devices, University of Electronic Science and Technology of China, \\ Chengdu, China and Research and Development Department, Guangdong Guanghua Sci-Tech Co., Ltd., Shantou, China \\ Vadim V. Silberschmidt \\ Wolfson School of Mechanical and Manufacturing Engineering, Loughborough University, Loughborough, UK, and \\ Ze Tan \\ Research and Development Department, Guangdong Guanghua Sci-Tech Co., Ltd., Shantou, China
}

\begin{abstract}
Purpose - The purpose of this paper is to form copper coin-embedded printed circuit board (PCB) for high heat dissipation.

Design/methodology/approach - Manufacturing optimization of copper coin-embedded PCB involved in the design and treatment of copper coin, resin flush removal and flatness control. Thermal simulation was used to investigate the effect of copper coin on heat dissipation of PCB products. Lead-free reflow soldering and thrust tests were used to characterize the reliable performance of copper coin-embedded PCB.

Findings - The copper coin-embedded PCB had good agreement with resin flush removal and flatness control. Thermal simulation results indicated that copper coin could significantly enhance the heat-dissipation rate by means of a direct contact with the high-power integrated circuit chip. The copper coin-embedded PCB exhibited a reliable structure capable of withstanding high-temperature reflow soldering and high thrust testing.

Originality/value - The use of a copper coin-embedded PCB could lead to higher heat dissipation for the stable performance of high-power electronic components. The copper coin-embedded method could have important potential for improving the design for heat dissipation in the PCB industry.
\end{abstract}

Keywords Reliability, Thermal simulation, Copper coin, Heat dissipation, Manufacture, PCB

\section{Introduction}

Multifunctional electronic devices with ultra-large-scale integration increase the requirements for rapid heat dissipation in printed circuit boards (PCB) with a growing interconnection density, as stable electrical performance and reliability are required during their high-power operation (Suppa, 2008; Chen et al., 2014a; Wang et al., 2009). Intensive drilling of holes and local thick copper plating are generally introduced into PCB manufacturing for thermal management but the interconnection density will be limited in designs with increasing holes and copper plating areas. Highly conductive inorganic fillers have also been added into insulating polymers to improve the heat dissipation, as most of the dielectric materials for PCBs are amorphous polymers with phonon scattering from numerous defects, leading to an extremely low thermal conductivity (Chen et al., 2013; Li et al., 2011; Jin et al., 2012). However, pure metals, with free electrons for rapid heat transport, possess such high thermal conductivities that metal plates can be used as heat sinks to significantly enhance the thermal design loads of PCBs (Chen et al., 2014b; Caisse et al., 2011; Buck, 1992). A PCB is

The authors gratefully acknowledge the support of Guangdong Innovative Research Team Program (no. 201301C0105324342), National Natural Science Foundation of China (no. 61474019) and also express their sincere thanks to the support of the China Scholarship Council (no. 201306070032).

Received 24 November 2014

Revised 24 November 2014

Accepted 27 February 2015 
usually bonded by means of an adhesive film with a whole metal plate as a bottom layer or a core inlayer to give a heat-dissipating construction (Wille, 2008; Cho and Hyeong, 2008) but this method can result in an increase both in the volume and weight of the PCB. In addition, a small size metal plate has been embedded into a PCB interior to promote heat dissipation (Cho, 2008), but heat could still be accumulated inside the PCB, thereby causing popcorning type problems. A small metal should be vertically inserted/embedded through all the layers of a PCB, so that heat could be immediately transferred from the component to the surrounding area of the PCB. In this way, a PCB with an embedded solid copper is proposed for a new design for thermal management.

In this work, a copper coin was embedded into the PCB system with a good manufacturing processes. The thermal behaviour of a copper coin-embedded PCB was simulated compared to that of a traditional PCB. The reliability of the copper coin-embedded PCB was also analyzed to investigate the stability of the structure.

\section{Experiment}

The manufacturing process of the copper coin-embedded PCB is outlined in Figure 1. Epoxy-glass material, copper foil and prepreg for the PCB laminates were stacked and riveted to form a laminate system after imaging and etching of the circuit patterns. Thereafter, a copper coin with a brown-oxide treatment was embedded into the window, which was routed in the above riveted laminate system. The laminate system with the copper coin was finally put into a hot press so that prepreg for bonding the laminates could fill into the interstices between the copper coin and the window during the curing process. The copper coin-embedded PCB was obtained after completely curing the prepreg. A scanning electron microscope and a metallographic microscope were used to observe the microstructure of the copper coin. Reliability testing of the copper coin-embedded PCB involved lead-free reflow soldering and thrust tests.

The thermal behaviour was simulated to investigate the heat dissipation of the copper coin-embedded PCB. Four integrated circuit (IC) chips with ball grid array packaging as the heat source were set at the surface of the copper coin-embedded PCB. The sizes of the above chips with powers of $0.8,1.2,1.0$ and $1.3 \mathrm{~W}$ were $10 \times 10 \mathrm{~mm}, 15 \times 15$ $\mathrm{mm}, 12 \times 12 \mathrm{~mm}$ and $18 \times 12 \mathrm{~mm}$, respectively. The sizes of the embedded copper coins were the same as those of the corresponding IC chips. The copper coin-embedded PCB was about $700 \mu \mathrm{m}$ in thickness. The model of the copper coin-embedded PCB was simplified for effective simulation using the following assumptions:

Figure 1 Manufacturing process of copper coin-embedded PCB

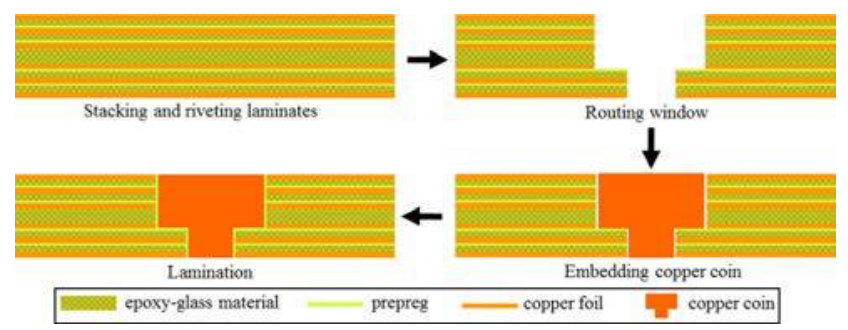

- through holes, microvias and circuit patterns could be neglected;

- thermal contact resistance between the IC chip and the PCB could be ignored;

- each layer of the PCB could be closely linked; and

- the IC chips could be considered as a steady heat source with uniform temperature distribution due to the extremely thin thickness of the IC chips compared to that of the PCB.

the thermal behaviour of a traditional PCB without the copper coins was also simulated for comparison.

\section{Results and discussion}

\subsection{Manufacturing optimization of the copper coin-embedded PCB}

The design and surface roughness of the copper coin plays a significant role in the bonding stability of the copper coins when embedded in the PCB. As shown in Figure 2, the copper coin was designed as a ladder shape with a bump in the middle, so that the bump for preferentially absorbing heat from IC chips could generate a chucking structure with the routed window, while the planar construction of the copper coin could increase the effective contact area with the prepreg, thereby leading to an increase in the bonding strength with the PCB laminates after curing the prepreg. However, as illustrated in Figure 3a, the microstructure of the solid copper was still not rough enough, so that the bonding strength between the copper and epoxy resin of the prepreg could be weakened. The copper coin should be treated by surface roughing to enhance the bonding strength before the embedding process. Figure $3 \mathrm{~b}$ shows that a rugged topography appeared at the surface of the copper coin after brown-oxide treatment, stemming from the synergistic effect of the microetching of the superficial copper and the generation of an organo-matallic complex coating (Bellakhal et al., 2000). In this way, the organo-matallic complex coating could enhance the interfacial connection between the inorganic solid copper and the organic epoxy resin. Hence, based on the special design and surface treatment of the

Figure 2 Design of copper coin for embedding in PCB laminates

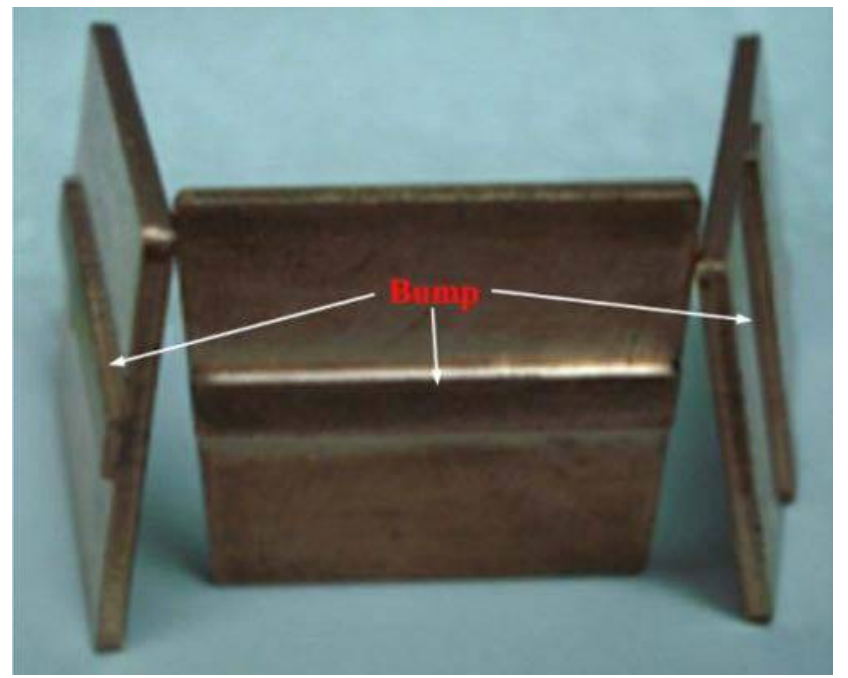


Figure 3 (a) Surface morphology of copper coin before brown-oxide treatment; (b) and after brown-oxide treatment

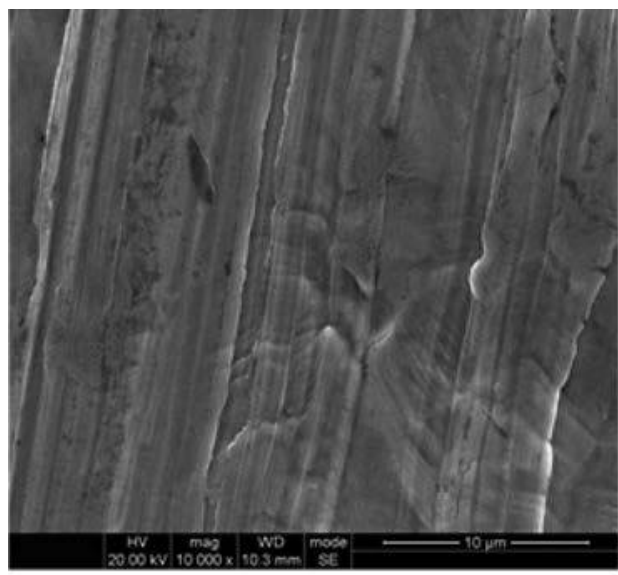

(a)

copper coin, the epoxy resin of the prepreg could contribute a strong adhesive strength to make the copper coin tightly bond with the PCB laminate.

During hot pressing for the lamination of the PCB system, the epoxy resin of the prepreg could be extruded from the interstices between the copper coin and the routing window, thereby generating resin flush at the surface of the copper foil, as shown in Figure 4a. However, the formation of circuit patterns could be hindered due to the presence of resin flush. Hence, a green solder resist ink with a $5-10 \mu \mathrm{m}$ thickness was deposited beforehand on the surface of the copper foil using a silk screen printing method. Thereafter, the interstices between the copper coin and the PCB laminate was exposed to let resin flush out during the hot pressing for curing the prepreg. After stripping the solder resist ink with a $\mathrm{NaOH}$ solution at $80^{\circ} \mathrm{C}$ for $40 \mathrm{~min}$, resin flush removal could also be carried out to reveal a clean copper surface, as shown in Figure $4 b$.

The flatness between the copper coin and the PCB system should also be considered because uneven heat distribution

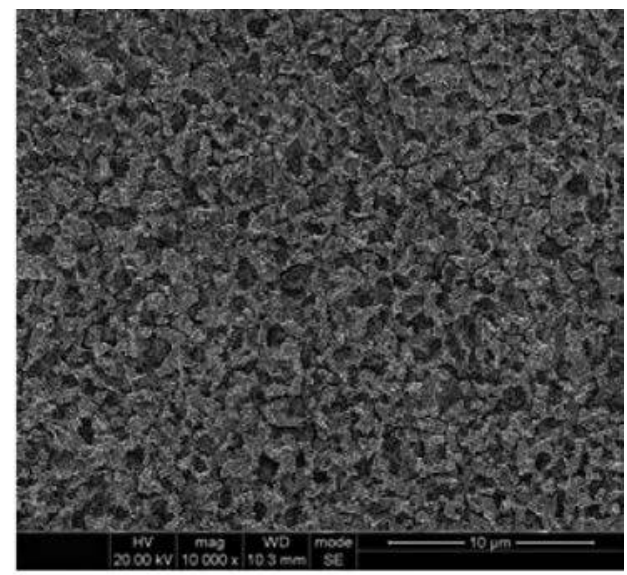

(b)

around the routing window would induce PCB bow/twist during hot pressing. Thin copper plates with a smaller size than the copper coin were used to cover the surface of the copper coin for steady heat distribution and for prevention of vertical movement of the copper coin during lamination. In this way, the height difference between the copper coin and the PCB system was $10.7 \mu \mathrm{m}$ at the top layer and $8.1 \mu \mathrm{m}$ at the bottom layer, as shown in Table I. Such small height differences indicated that the copper coin-embedded PCB exhibited good flatness between the copper coin and the PCB system.

Electroless nickel/immersion gold deposition and solder resist ink printing were thereafter preformed to give the finished copper coin-embedded PCB. It was found, in Figure 5, that the PCB product exhibited good embedding quality of the copper coin, with optimized manufacturing, design and pre-treatment of the copper coin, resin flush removal and flatness control between the copper coin and the PCB system.

Figure 4 (a) PCB with resin flush; (b) and without resin flush after hot-press lamination
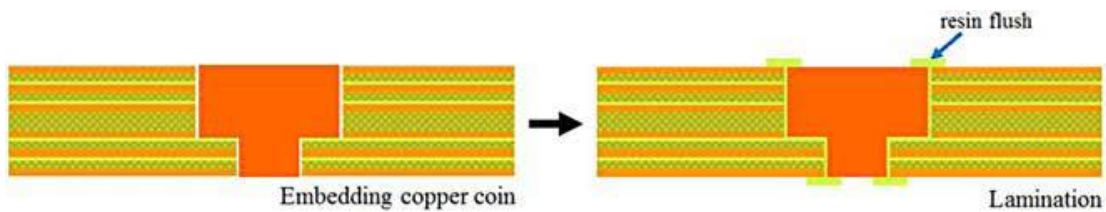

(a)

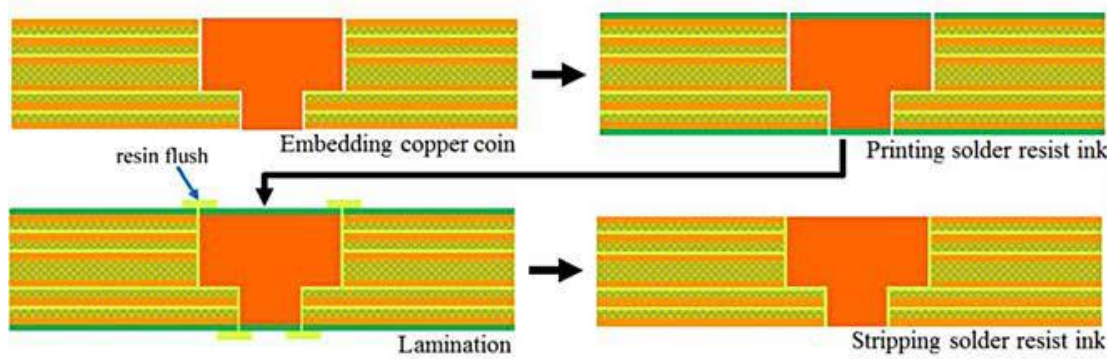

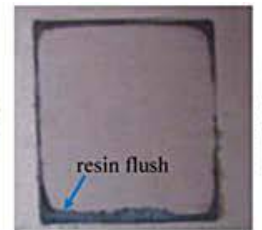
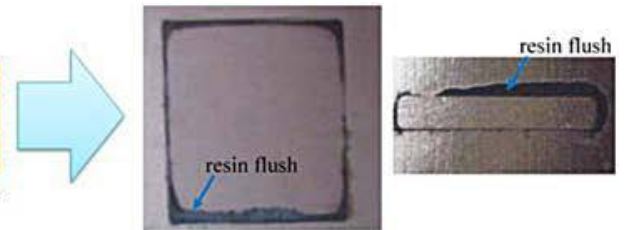

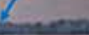

.
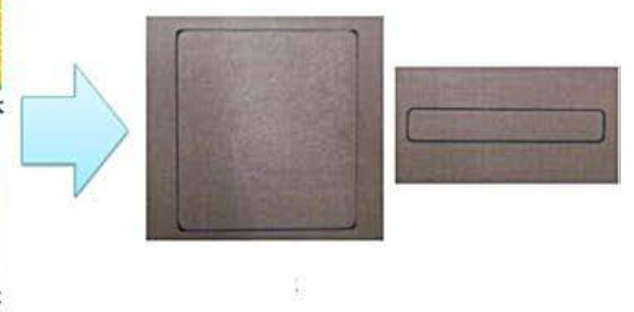
Table I Height difference between copper coin and PCB system

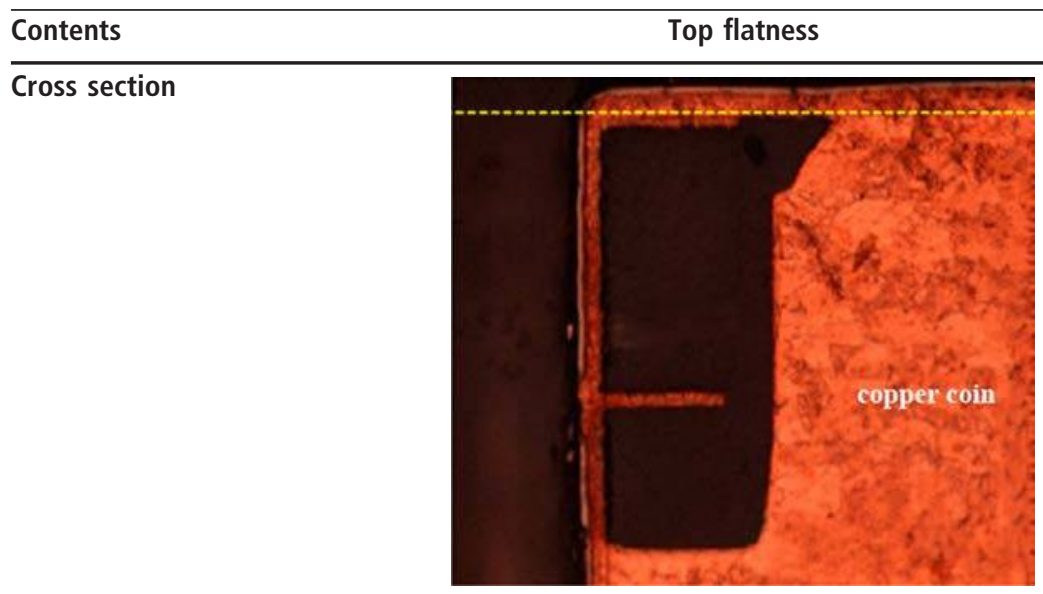

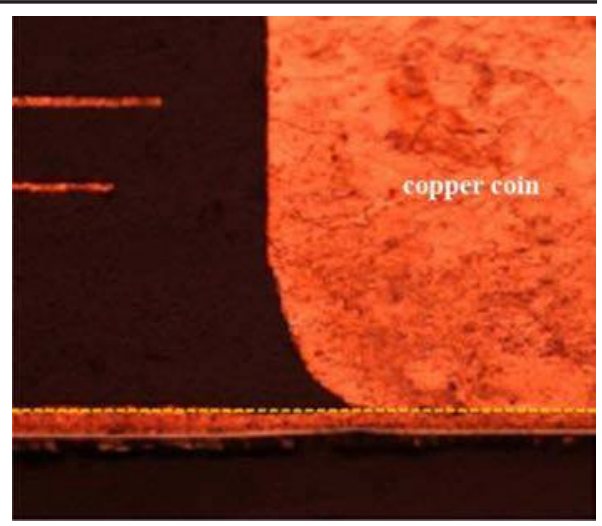

8.1
Figure 5 PCB system with a well-embedded copper coin
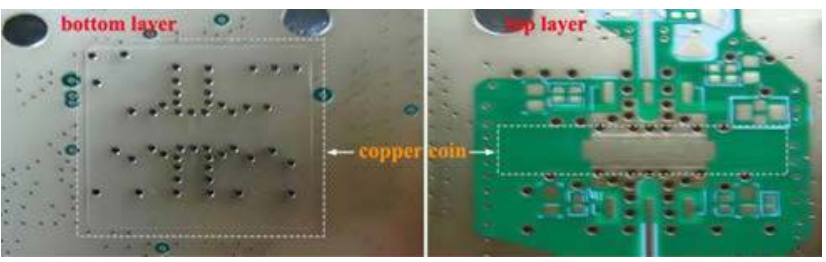

\subsection{Thermal dissipation simulation of a copper coin-embedded PCB}

During the steady thermal simulation, a PCB with IC chips as a heat source worked in the following environment; a temperature of $25^{\circ} \mathrm{C}$ and a natural convection flow with a convection coefficient of $20 \mathrm{Wm}^{-2} \mathrm{~K}^{-1}$. Figure 6 displays the three-dimensional structure and temperature distribution of the copper coin-embedded PCB, compared with the case for a

Figure 6 (a) Thermal simulation of traditional PCB; (b) and a copper coin-embedded PCB
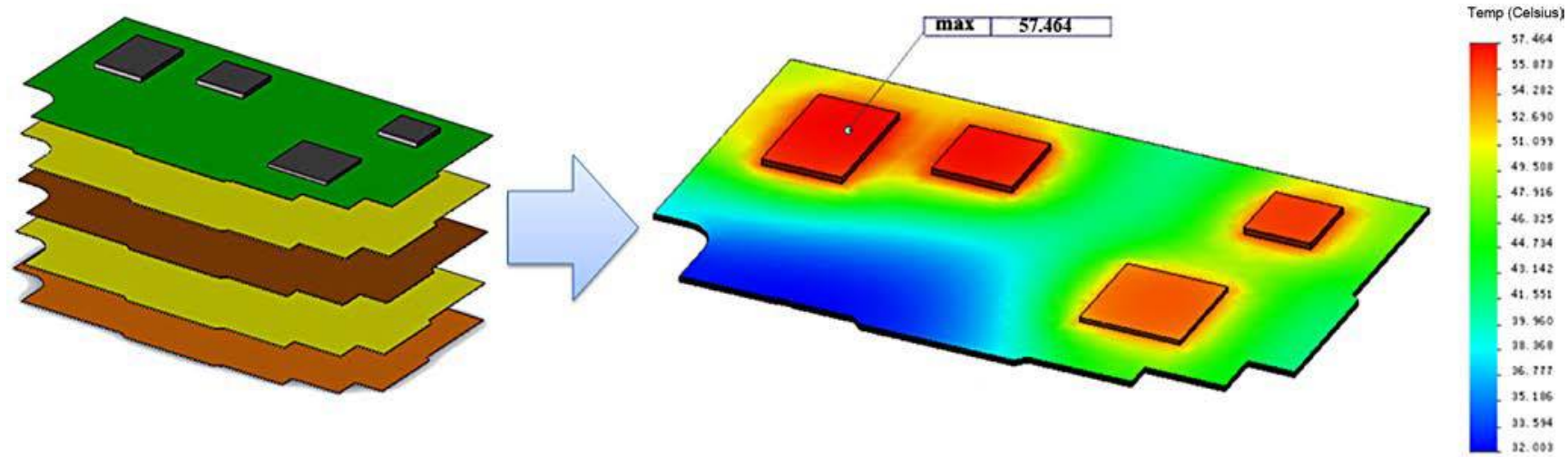

(a)
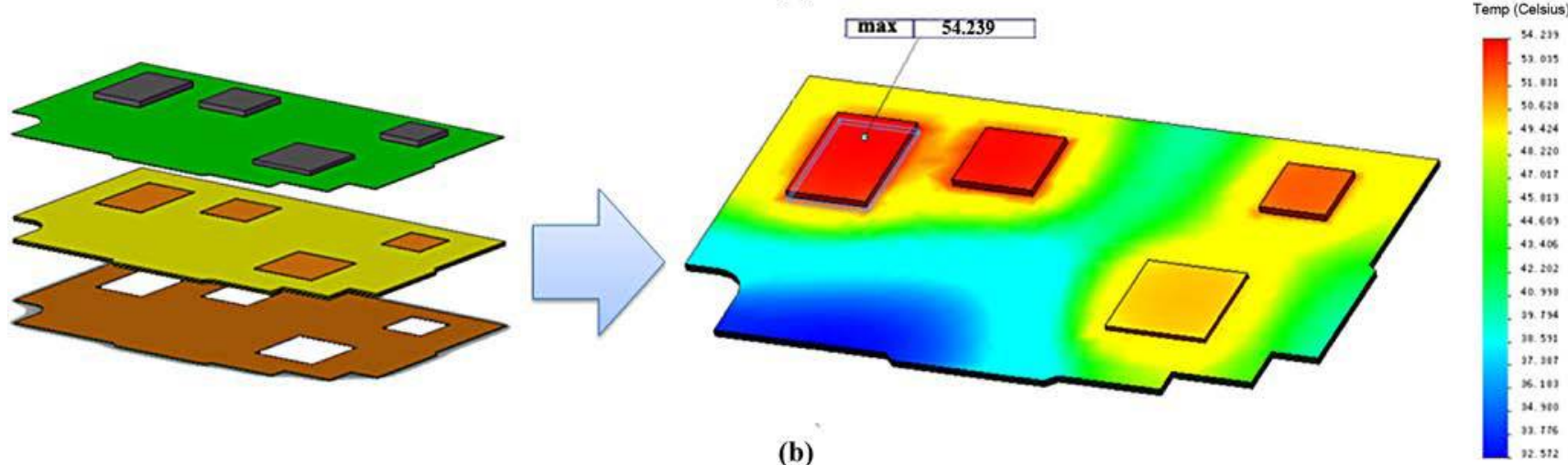

(b) 
traditional PCB. It was found that the traditional PCB and the copper coin-embedded PCB both exhibited the same trend of temperature: the working temperature decreased from the IC chips to the PCB edge. However, the presence of the high thermally conductive copper coin could result in faster heat dissipation around the corresponding IC chip. The maximal working temperature of the PCB with an embedded copper coin reached $54.2^{\circ} \mathrm{C}$ (Figure $6 \mathrm{~b}$ ), $3.2^{\circ} \mathrm{C}$ lower than that of the traditional PCB (Figure 6a). In addition, the heat diffusive area of the PCB was enlarged, thereby avoiding heat accumulation in a limited area surrounding the IC chip. This meant that the copper coin in a PCB could contribute to high heat transport towards the surrounding area and the ambient environment with the direct contact between the copper coin and the IC chip.

Transient temperature variation was also simulated to investigate the thermal diffusion of the PCB. The temperature trend of the IC chip with $1.3 \mathrm{~W}$ was recorded as a function of time. As illustrated in curve a of Figure 7, the traditional PCB had a significant increase in temperature from 0 to $80 \mathrm{~s}$, but the increase in rate slowed down after $80 \mathrm{~s}$. This was ascribed to the low heat dissipation of the IC chip towards the surrounding PCB material. In this way, the final temperature of the IC chip in a traditional $\mathrm{PCB}$ at $300 \mathrm{~s}$ was $56.9^{\circ} \mathrm{C}$ in the condition of thermal diffusion equilibrium and steady working of the IC chip. However, the temperature for the same IC chip in a copper coin-embedded PCB reached stability in 50s, as shown in Curve $\mathrm{b}$ of Figure 7. The final temperature of the IC chip in the copper coin-embedded PCB gradually increased to $49.2^{\circ} \mathrm{C}$ at $300 \mathrm{~s}$, $7.7^{\circ} \mathrm{C}$ lower than the case for the traditional PCB. The copper coin provided a highly thermally conductive medium for the IC chip to efficiently transport heat, so that the IC chip exhibited a smaller final temperature and a quicker heat steady state.

The effect of different convection coefficients on temperature variation was also simulated to investigate the performance of the copper coin on heat dissipation. The maximal temperature of the same IC chips in a traditional PCB and a copper coin-embedded PCB both decreased as the increment of the convection coefficients, as shown in Figure 8. However, a copper coin-embedded PCB with high heat

Figure 7 Temperature variation with transient thermal simulation of traditional PCB (I) and a copper coin-embedded PCB (II), as a function of time

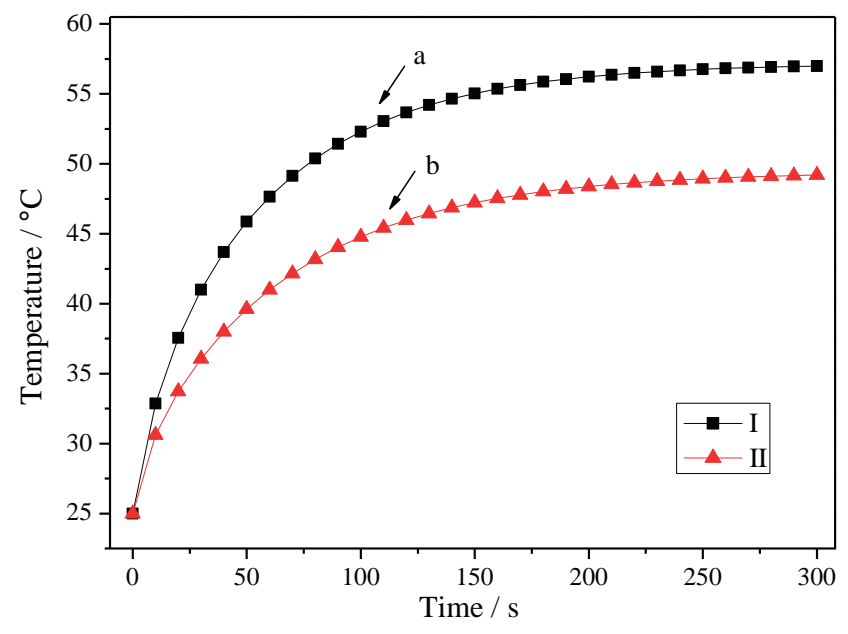

Figure 8 Temperature variation of traditional PCB (I) and copper coin-embedded PCB (II) as a function of convection coefficient

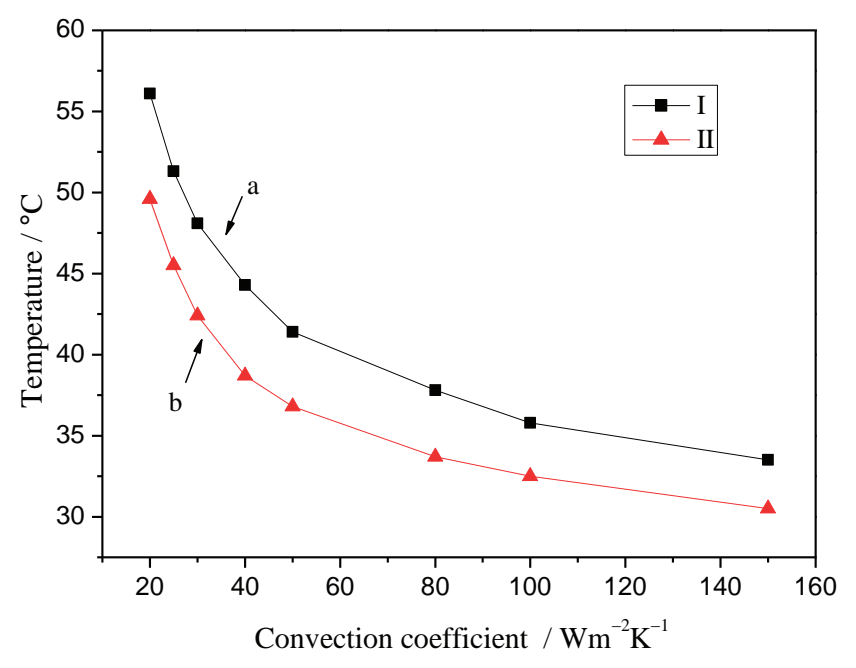

dissipation exhibited a smaller temperature than a traditional PCB at the same convection coefficient. The temperature difference of the copper coin-embedded PCB and the traditional $\mathrm{PCB}$ reached $3^{\circ} \mathrm{C}$ at the convection coefficient of $150 \mathrm{Wm}^{-2} \mathrm{~K}^{-1}$. Thus, it was also found that the copper coin could enhance heat transport with the increase of the convection coefficient.

In summary, the results of the thermal simulation indicated that the presence of a copper coin could lead to improvement of the heat conduction. In this way, a copper coin-embedded PCB product could provide good working conditions with a lower system temperature for electronic components, thereby improving the performance of a PCB system with high-power IC chips.

\subsection{Reliable characterization of copper coin-embedded PCB}

During lead-free reflow soldering tests, PCBs can exhibit the popcorning problem between layers due to thermal stress under thermal shock (Guojun and Tay, 2005). Although an embedded copper coin changed the structure of the traditional system, it could also act as a thermal conductor to decrease the heat accumulation in a PCB, thereby helping to avoid popcorning problems. According to the cross-section micrographs in Figure 9, the popcorn problem was apparently not found in the copper coin-embedded PCB system after lead-free reflow soldering testing. On the other hand, the bonding strength of the cured prepreg between the layers was still high enough to maintain the stable structure of the copper coin-embedded PCB.

Thrust was applied to the surface of the bump of the copper coin to characterize the bonding strength of the copper coin with the epoxy of the prepreg. The applied thrust was increased to gradually break the copper coin away from the PCB system during the first stage, as shown in Figure 10. However, the thrust remained the same, at about $90 \mathrm{~N}$, in the displacement of the copper coin ranging from 0.3 to $0.6 \mathrm{~mm}$. Molecular chains in the epoxy could be transferred to orient their texture along the thrust direction to resist the deformation of the viscous force for the copper coin. Hence, the resistive force from the epoxy could be 
Figure 9 Cross-section micrographs of copper coin-embedded PCB after lead-free reflow soldering
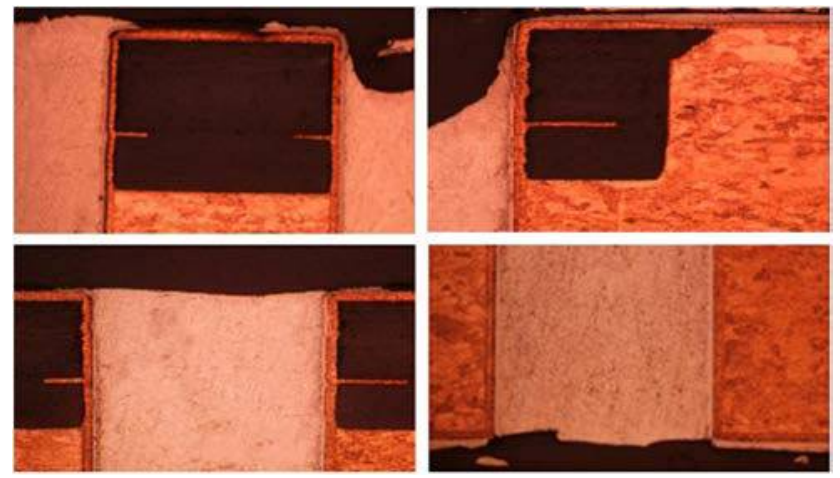

Figure 10 Thrust test for breaking copper coin from PCB system

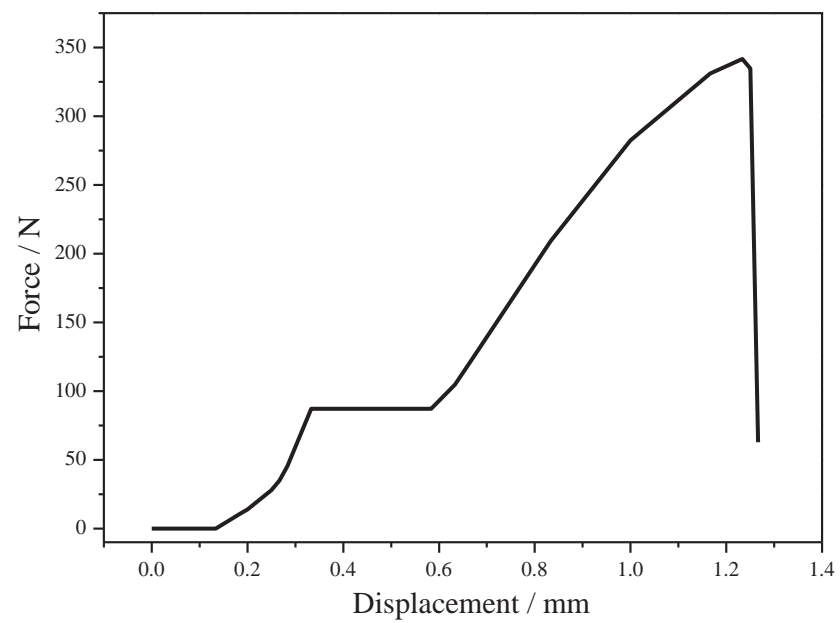

equal to the applied thrust at the copper coin during the second stage. At the next stage, the thrust continued to significantly increase because the obstacle of polymeric strong networks was finally broken. The copper coin was completely separated from the PCB system when the thrust reached about $340 \mathrm{~N}$. This revealed that the bonding strength for the copper coin was high enough to meet the requirements of a stable combination in a PCB system.

\section{Conclusions}

The manufacture of a copper coin-embedded PCB was optimized to prevent the occurrence of resin flush and to carry out flatness control between the copper coin and the PCB system. Thermal simulation results indicated that the copper coin could significantly enhance the heat-dissipation rate when in direct contact with a high-power IC chip. The copper coinembedded PCB exhibited a reliable structure capable of withstanding high-temperature reflow soldering and high thrust testing.

\section{References}

Bellakhal, N., Draou, K., Addou, A. and Brisset, J.L. (2000), "Cleaning of copper foil coated with sodium hexanoate as corrosion inhibitor", fournal of Applied Electrochemistry, Vol. 30 No. 5, pp. 595-600.

Buck, T.J. (1992), "Advanced metal core substrates as a solution for multichip module backplanes", Circuit World, Vol. 18 No. 2, pp. 20-26.

Caisse, C.J., Coonrod, J. and Horn, A.F. (2011), "Measurement of simulated active device and RF trace heating in high frequency circuit laminates", Circuit World, Vol. 37 No. 4, pp. 3-9.

Chen, Y., He, W., Chen, X., Wang, C., Tao, Z., Wang, S., Zhou, G. and Moshrefi-Torbati, M. (2014a), "Plating uniformity of bottom-up copper pillars and patterns for IC substrates with additive-assisted electrodeposition", Electrochimica Acta, Vol. 120 No. 1, pp. 293-301.

Chen, Y., He, W., Zhou, G., Tao, Z., Wang, Y. and Luo, D. (2013), "Failure mechanism of solder bubbles in PCB vias during high-temperature assembly", Circuit World, Vol. 39 No. 3, pp. 133-138.

Chen, Y., He, W., Zhou, G., Hu, Y., Wang, S. and Tao, Z. (2014b), "Preparation and thermal effects of polyarylene ether nitrile aluminium nitride composites", $\underline{\text { Polvmer }}$ International, Vol. 63 No. 3, pp. 546-551.

Cho, H.M. and Joon Kim, H. (2008), "Metal-core printed circuit board with alumina layer by aerosol deposition process", IEEE Electron Device Letters, Vol. 29 No. 9, pp. 991-993.

Cho, S.H. (2008), "Heat dissipation effect of Al plate embedded substrate in network system", Microelectronics Reliabilitv, Vol. 48 No. 10, pp. 1696-1702.

Guojun, H. and Tay, A.A. (2005), "On the relative contribution of temperature, moisture and vapor pressure to delamination in a plastic IC package during lead-free solder reflow", Proceedings of 55th IEEE Electronic Components and Technology Conference, pp. 172-178.

Jin, F.L. and Park, S.J. (2012), "Thermal properties of epoxy resin/filler hybrid composites", Polvmer Degradation and Stability, Vol. 97 No. 11, pp. 2148-2153.

Li, S., Qi, S., Liu, N. and Cao, P. (2011), "Study on thermal conductive BN/novolac resin composites", Thermochimica Acta, Vol. 523 No. 1, pp. 111-115.

Suppa, M. (2008), "The process and pastes for the via hole plugging of HDI PCBs", Circuit World, Vol. 34 No. 1, pp. 25-31.

Wang, X.C. and Zheng, H.Y. (2009), "High quality laser cutting of electronic printed circuit board substrates", Circuit World, Vol. 35 No. 4, pp. 46-55.

Wille, M. (2008), "Methods for dissipating heat from RF circuit boards", Circuit World, Vol. 34 No. 1, pp. 32-34.

\section{Corresponding author}

Yuanming Chen can be contacted at: yuangmingde@ 163.com 